\title{
Indicadores de Avaliação das Compras da Agricultura Familiar para Alimentação Escolar no Paraná, Santa Catarina e São Paulo ${ }^{1}$
}

\author{
José Giacomo Baccarin², Rozane Marcia Triches ${ }^{3}$ \\ Carla Rosane Paz Arruda Teo ${ }^{4}$ e Denise Boito Pereira da Silva ${ }^{5}$
}

Resumo: O objetivo é propor uma sistematização de diversas variáveis que contribuam para a avaliação das compras da agricultura familiar para a alimentação escolar, apresentando resultados para o Paraná, Santa Catarina e São Paulo. Procurou-se verificar a eficiência das Chamadas Públicas (CPs) em alcançar o público pretendido, a eficácia em contribuir para maior volume de compras dos agricultores familiares (AFs) e maior consumo de produtos in natura e menos processados, bem como a efetividade relativa aos efeitos na renda e organização dos agricultores. Os dados foram coletados de CPs, contratos de fornecimento e prestações de contas das prefeituras. Verificou-se que o cumprimento da legislação vem crescendo, embora o número potencial de agricultores familiares atendíveis seja relativamente pequeno na maioria dos municípios. Os preços são mais altos que em mercados convencionais e, nas compras, predominam produtos vegetais in natura ou com baixo grau de processamento, beneficiando escolares e agricultores familiares. Contudo, em vários casos as CPs apresentam debilidades, como a falta de informações, a frequência e o número de locais de entrega e os preços a serem pagos, o que prejudica a organização dos AFs e a eficiência do processo. Observou-se estímulo ao aumento da formalidade jurídica e de organização dos agricultores.

Palavras-chaves: Agricultura familiar, compras públicas, alimentação escolar, mercados institucionais, abastecimento.

Abstract: The aim of this study is to propose a systematization of several variables that contribute to the evaluation of purchases from family farming for school feeding,

DOI - http://dx.doi.org/10.1590/1234-56781806-94790550106

1. Data de submissão: 9 de novembro de 2015. Data de aceite: 17 de outubro de 2016.

2. Universidade Estadual Paulista Júlio de Mesquita Filho, Jaboticabal, São Paulo, Brasil. E-mail: baccarin@fcav.unesp.br

3. Universidade Federal da Fronteira Sul, Realeza, Paraná, Brasil. E-mail: rozane.triches@gmail.com

4. Universidade Comunitária da Região de Chapecó, Chapecó, Santa Catarina, Brasil. E-mail: carlateo@unochapeco.edu.br

5. Universidade de São Paulo, Ribeirão Preto, São Paulo, Brasil. E-mail: denise_bps@hotmail.com 
presenting results for Paraná, Santa Catarina and São Paulo. This is based on the assessment of the efficiency of the Public Calling (CPs) to achieve the desired and effective public to contribute to higher purchases of family farmers (households) and increase consumption by students of fresh and less processed products, also the relative effectiveness of the effects on income and organization of farmers. Data were collected from CPs, supply contracts and municipalities accounts. It was found that compliance with legislation is growing, although the potential number of family farmers is relatively small in most municipalities. In the contracts, the prices are higher than in conventional markets and in natura or less processed products predominate among purchases, favoring school and family farmers. However, in several cases the CPs have weaknesses, such as lack of information, the frequency and the number of delivery locations and the prices to be paid, which affects the organization of households and process efficiency. It was observed encouragement to the increase of legal formality and the organization of farmers.

Key-words: Family farming, public purchases, school feeding, institutional markets, supply.

Classificação JEL: Q18.

\section{Introdução}

Em julho de 2003 foi aprovada no Brasil a Lei Federal no 10.696 (BRASIL, 2003), instituindo o Programa de Aquisição de Alimentos da Agricultura Familiar (PAA). Assumia-se a intenção de garantir a compra, a preços mais remuneradores do que os tradicionais, de produtos alimentícios de agricultores familiares, ao mesmo tempo que se propunha a destiná-los para consumo de pessoas em insegurança alimentar. Desde o início, observou-se que parte significativa dos produtos adquirida através do PAA destinava-se à alimentação escolar gerenciada por governos estaduais e prefeituras municipais.

Ao exemplo do PAA e de algumas experiências exitosas neste campo, em junho de 2009 foi aprovada a Lei Federal no 11.947 (BRASIL, 2009a), que passava a regulamentar a aquisição de produtos da agricultura familiar para o Programa Nacional de Alimentação Escolar (PNAE), em seu artigo 14. Neste é determinado que, do total de recursos financeiros repassados pelo Fundo Nacional de Desenvolvimento da Educação (FNDE) aos estados e municípios para gastos com a alimentação escolar, no mínimo 30\% devem ser utilizados na aquisição de gêneros alimentícios oriundos de agricultores familiares ou de suas organizações.

Dessa forma, o artigo 14 se apresenta de forma mais incisiva, estabelecendo porcenta- gem obrigatória mínima de aplicação dos recursos repassados pelo FNDE, enquanto no PAA não há vinculação orçamentária previamente definida. Ressalte-se que os repasses dos recursos do FNDE baseiam-se no número de alunos e em valor monetário per capita para cada dia do calendário escolar, de acordo com a Resolução do FNDE n. 26 de 2013 (BRASIL, 2013a).

A Resolução do FNDE no 38 de 2009 (BRASIL, 2009b), primeira regulamentação da Lei ํㅡㄴ 11.947, define que, frente à dispensa licitatória, se utilize a chamada pública $(\mathrm{CP})$ como instrumento para aquisição dos produtos da agricultura familiar. Levando-se em conta que se pretende garantir preços mais justos aos agricultores familiares, a $\mathrm{CP}$, a partir de critérios explicitados adiante, deve fixá-los previamente, não podendo se constituir em objeto de disputa entre os agricultores familiares.

A legislação também prevê que terão prioridade no certame os agricultores locais (do município). $\mathrm{Na}$ impossibilidade disso, a prioridade será para agricultores do território rural, seguidos por agricultores do estado e, por fim, caso necessário, por agricultores de outros estados. Assim, o programa procura trabalhar com os chamados circuitos curtos de comercialização e com a movimentação local dos recursos públicos recebidos. Tais circuitos se mostram adequados à comercialização de produtos in natura, cujo aumento de 
consumo também se apresenta como um dos objetivos da Lei no 11.947 .

Este novo olhar para os Programas de Alimentação Escolar vem sendo nominado na literatura internacional de Home-Grown School Feeding - HGSF (ESPEJO, BURBANO e GALLIANO, 2009; BUNDY et al., 2009). Ou seja, a combinação do incentivo à produção agrícola local com a qualificação dos programas de alimentação escolar tem como premissa básica que a baixa produtividade, o frágil desenvolvimento de mercados agrícolas locais e os restritos resultados nutricionais e educacionais são mutuamente reforçados e determinam insegurança alimentar e pobreza. O HGSF trabalharia como um ponto de sinergia entre os objetivos de aumento da renda dos agricultores, do desenvolvimento local e de saúde pública por meio de programas de alimentação como o PNAE (TRICHES, 2015).

É importante se acrescentar que a experiência institucional brasileira, de readequação da alimentação escolar aos ditames do HGSF, tem servido de exemplo a outros países, em especial da África e da América Latina. Estes têm se espelhado no Brasil para (re)elaborar e (re)construir seus programas de alimentação escolar com vistas a utilizar os mesmos recursos investidos na alimentação dos escolares para promover o desenvolvimento socioeconômico (FAO, 2013; TRICHES, SCHNEIDER e SIMÕES, 2013).

Além de favorecer a produção local e estimular as cadeias curtas de abastecimento, a nova legislação do PNAE estabelece que, nas compras, devam ser priorizados públicos específicos, como os assentados da reforma agrária, quilombolas e indígenas, os que produzem de forma orgânica/ agroecológica e os organizados em cooperativas ou associações, nesta ordem. Ou seja, incorpora questões socioculturais, organizativas e ambientais como balizadores das compras institucionais de agricultores familiares.

A alimentação escolar é um direito constitucional e, portanto, se estabelece como política permanente de Estado. Pelo fato de o artigo 14 ser uma legislação ainda recente, é importante que se realizem estudos que permitam acompanhar sua aplicação, o que já vem ocorrendo em várias regiões do País. Estudos de Saraiva et al. (2013) e de Soares et al. (2013) demonstram que 47,4\% dos municípios brasileiros já adquiriam alimentos da agricultura familiar um ano após a lei n. 11.947, e que o percentual de compra nestes municípios era, em média, de 22,7\% dos repasses do FNDE. A região Sul do País apresentava o maior percentual de municípios comprando alimentos da agricultura familiar (71,3\%), e a Centro-Oeste, o menor (35,3\%). Em 2012, a proporção dos municípios participantes aumentou para $67 \%$, sendo que a região Sul atingiu $87 \%$, tendo em vista o "alto nível dos capitais físicos e sociais, incluindo os altos níveis de afiliação cooperativa" (SOARES et al., 2013, p. 22).

Segundo dados mais recentes, disponíveis no site do FNDE (2015), os percentuais de municípios que compravam alimentos de agricultores familiares no País em 2013 e 2014 foram de 84\% e $89 \%$, respectivamente. Os municípios do Rio Grande do Sul, em conjunto, gastaram próximo a $40 \%$ dos repasses do FNDE com produtos de agricultores familiares em 2014, maior proporção do País, enquanto no Amapá esse índice não passou de $4,2 \%$, o menor dentre todos os estados.

Por outro lado, várias pesquisas têm verificado dificuldades para o agricultor acessar e permanecer neste mercado. Isso se relaciona a questões operacionais, estruturais e políticas como a organização dos agricultores, a dificuldade de logística, os preços pagos pelos produtos, a falta de formação e informação dos atores envolvidos, a falta de documentação dos agricultores, a desconfiança dos mesmos em relação ao poder público, a informalidade das agroindústrias, as estruturas inadequadas nas escolas, a falta de articulação entre os gestores e os agricultores e celeumas políticas (BACCARIN et al., 2011; CORA e BELIK, 2012; TRICHES e SCHNEIDER, 2012; BEZERRA et al., 2013; SARAIVA et al., 2013; SOARES et al., 2013; BEVILAQUA e TRICHES, 2014; TRICHES e GRISA, 2015).

Para colaborar neste debate, e ainda medir a eficiência, a eficácia e a efetividade desta polí- 
tica de compras institucionais, este estudo tem o objetivo principal de propor uma sistematização de diversas variáveis (indicadores) que contribuam para a avaliação da sua aplicação local. Tal proposta foi sendo amadurecida a partir da consulta da literatura já existente e na execução, pelos autores do artigo, de pesquisas e ações de extensão acadêmica, como seminários e capacitações, que possibilitaram a consulta a diversos documentos públicos e entrevistas/contatos com atores sociais envolvidos na aplicação do artigo 14 , a partir de alguns projetos de pesquisa. ${ }^{6}$

O outro objetivo é apresentar análises de algumas das variáveis apontadas e que puderam ser mensuradas a partir de dados e informações acumuladas nos últimos anos pelos autores e que dizem respeito aos municípios do Paraná, Santa Catarina e São Paulo. Especialmente, tem-se o interesse de identificar se os municípios são eficientes no atendimento ao artigo 14 da lei no 11.947 e até que ponto são eficazes em atingir os objetivos da legislação relacionados ao fortalecimento da agricultura familiar e à melhoraria da qualidade da alimentação escolar, decorrente do aumento do uso de alimentos in natura e menos processados, e quais efeitos já se pode perceber na vida e ação social dos agricultores familiares.

Cada um dos objetivos relaciona-se com uma das duas seções apresentadas a seguir, a segunda

6. a) "Reconhecimento e Gestão de Políticas Públicas de Segurança Alimentar: o Caso do Programa de Aquisição de Alimentos da Agricultura Familiar e da Implantação da Lei no 11.947 no Estado de São Paulo", contemplada com recursos da "Chamada MCT-Secis/CNPq, número 019/2010, com Propostas de Pesquisa em Tecnologias Sociais em Segurança Alimentar e Nutricional". Vigência 2010-2012; b) "Agricultura Familiar sob a Vigência da Lei Federal no 11.947/2009: Abrangência e Adequação das Chamadas Públicas, Impactos na Agricultura Local e Preços Recebidos pelos Agricultores Familiares", contemplada com recursos da "Chamada MCTI-CNPq/ MDS-SAGI, número 24/2013, Desenvolvimento Social”. Vigência 2013-2015; c) "Efeitos das Compras Institucionais via Programa de Aquisição de Alimentos e Programa Nacional de Alimentação Escolar nas Condições de Vida de Agricultores Familiares e no Desenvolvimento Local: Estudo e Aplicação em três Regiões do Estado de São Paulo e Articulações com Países da Unasul”, contemplado com recursos da "Chamada MCTI/Ação Transversal - Lei/ CNPq no 82/2013 Segurança Alimentar e Nutricional no Âmbito da Unasul e África". Vigência 2013-2015. com natureza metodológica e a terceira com apresentação de resultados. $\mathrm{O}$ artigo encerra-se com algumas considerações finais.

\section{Dificuldades, possibilidades e alcance do artigo 14 - como avaliá-las?}

A discussão acadêmica sobre a avaliação de políticas públicas, em especial as chamadas políticas sociais, é bastante ampla, sendo comum que se procure desenvolver indicadores quanti e qualitativos para este intento. Muitos autores, como Marinho e Façanha (2001), afirmam que seria procedente sistematizar os indicadores e realizar a avaliação das políticas públicas através dos critérios de eficiência, eficácia e efetividade. A eficiência diz respeito à otimização da aplicação dos meios (métodos, recursos financeiros, materiais, pessoais) em relação aos resultados alcançados pelo projeto ou política. Já a eficácia está relacionada com a capacidade demonstrada pelo projeto/política em atingir os objetivos e metas previamente estabelecidos. Tais critérios, portanto, avaliam mais especificamente a ação do órgão executor do projeto/política. Por sua vez, a efetividade mostra a capacidade que os resultados do projeto/política têm de produzir mudanças significativas e duradouras no público beneficiário. Ou seja, a ocorrência e abrangência da mudança na vida do público beneficiário que decorreram da execução do projeto/política (MARINHO e FAÇANHA, 2001).

O objeto deste artigo, a aplicação do artigo 14, pressupõe importantes (e desafiadoras) mudanças na execução de uma relativamente antiga ação de segurança alimentar e nutricional, a alimentação escolar, comumente denominada de merenda escolar. De parte do agente público local ou regional que a gerencia, espera-se que promova alterações no cardápio, às vezes com a incorporação de produtos que exigem maior manipulação no preparo das refeições, e nos processos de compras de produtos para alimentação escolar, bem como na articulação dos diversos setores administrativos 
envolvidos. Por seu lado, o agricultor familiar se defronta com diversas questões ligadas à formalidade jurídica e à capacidade de associação, bem como às características de sua produção, como regularidade, qualidade, sanidade e grau de processamento do produto.

Procura-se organizar, a seguir, um conjunto de variáveis relacionadas à aplicação do artigo 14 e que envolvem ações e estímulos das prefeituras municipais e dos agricultores familiares, em quatro diferentes tópicos. Para cada uma das variáveis é sugerida a forma como ela pode ser medida e que tipo de documento ou outra fonte de informação deve ser acessado. Com isso, quer-se contribuir para a formulação de ferramentas que consigam ter maior precisão na aferição do artigo 14 sob os quesitos da eficiência, eficácia e efetividade.

\subsection{Papel das prefeituras municipais}

Inicialmente, convém tecer breves comentários sobre o papel de diferentes esferas de governo na gestão da alimentação escolar na pré-escola e no ensino fundamental. Em 1994, o governo federal passou a descentralizar os seus recursos financeiros para os estados, municípios e escolas (Entidades Executoras) realizarem as compras de alimentos e fornecerem as refeições ao alunado. Com isso, poderiam ser reduzidos os custos logísticos e administrativos e se potencializaria o controle social sobre as ações do PNAE, já que, para tanto, todas as Entidades Executoras deveriam constituir o Conselho de Alimentação Escolar.

É comum que, aos recursos repassados pela União, via FNDE, estados e municípios agreguem recursos próprios para compra de alimentos, além de garantirem a estrutura física e o pessoal encarregado da alimentação escolar. Também pode acontecer que a gestão da alimentação escolar fique a cargo dos municípios mesmo em escolas estaduais localizadas em seu território. Tal arranjo é predominante no estado de São Paulo, por exemplo (SÃO PAULO, 2015).

A substituição das licitações convencionais pelas compras via chamadas públicas impõe a necessidade de adaptações nas ações das prefeituras municipais. Grande parte delas, tradicionalmente, organizava suas compras de produtos alimentícios através de licitações com participação de empresas fornecedoras especializadas, normalmente não localizadas no município e que ofereciam, no mais das vezes, produtos com considerável grau de processamento, facilmente armazenáveis e exigindo pouca manipulação por parte das funcionárias encarregadas do preparo da refeição escolar. Ao grosso das compras, feito dessa forma, as prefeituras podiam adicionar produtos comprados localmente, como panificados, frutas, legumes e verduras, especialmente.

Ao que parece, um ponto-chave para verificar a adequação das prefeituras ao artigo 14 são as modificações no cardápio da alimentação escolar, adaptando-os às condições produtivas dos agricultores familiares. Deve-se considerar, contudo, que nem toda modificação recente teve esse propósito, mas muitas foram consequências dos maiores cuidados com a qualidade nutricional que os serviços municipais passaram a revelar de alguns anos para cá, inclusive com a obrigatoriedade de se contar com profissional de nutrição na equipe de alimentação escolar a partir de 2006, com a resolução do FNDE no 32/2006 (BRASIL, 2006).

Mesmo havendo vontade do poder público, deve-se considerar que existem barreiras sanitárias e tecnológicas que dificultam a compra direta de produtos da agricultura familiar, especialmente os de origem pecuária. Ovos e mel podem ser comprados sem maiores transformações, mas os diversos tipos de carne e leite, necessariamente, têm que ser processados em agroindústrias, frigoríficos e laticínios, seguindo os regramentos sanitários existentes e sendo inspecionados pelos serviços municipais, estaduais ou federais.

Para além dos produtos de origem animal, existem várias possiblidades de as prefeituras abrirem espaço para os produtos de agricultores familiares, comprando produtos in natura ou com baixo nível de processamento como feijão, legumes, verduras e frutas frescas. Pode-se supor, inclusive, que as prefeituras adquiram pequenos 
maquinários e equipamentos para extração de suco de frutas compradas de agricultores familiares, como abacaxi e laranja, esta última muito importante no estado de São Paulo.

Uma maneira de se verificar o comprometimento das prefeituras com esse ponto é analisar o grau de processamento dos produtos que são solicitados nas chamadas publicas. Nesse sentido, sugere-se que, adaptando-se a proposta de Monteiro et al. (2010), incluindo-se produtos in natura, os alimentos sejam classificados em: i) in natura, que não passam por nenhum processamento; ii) com mínimo grau de processamento, que passam apenas por transformações físicas; iii) com médio grau de processamento, com transformações físico-químicas; iv) com alto grau de processamento, que necessitam transformação industrial fora do espaço produtivo do agricultor familiar e suas organizações. A suposição que se estabelece é que quanto menor o grau de processamento e industrialização exigido, mais adaptadas as chamadas públicas estariam às condições dos agricultores familiares.

Um comprometimento maior das prefeituras com os agricultores e o desenvolvimento local se evidenciaria ao se promoverem modificações no cardápio para contemplar alimentos produzidos no próprio município ou na região, inclusive considerando sua sazonalidade. Alguns exemplos podem ser citados, com a substituição de fontes de carboidratos - batata inglesa por mandioca ou vice-versa -, a incorporação de peixe na alimentação escolar em regiões com piscicultura desenvolvida, o uso de mel em lugar do açúcar da cana etc.

Desse ponto deriva algo mais desafiador e de difícil implantação (aliás, não só para o programa aqui analisado), que seria a integração de diferentes setores públicos, no caso em análise, da alimentação escolar e de fomento agropecuário, não esquecendo as mudanças necessárias nos trâmites administrativos. Além da adaptação do cardápio às condições locais, pode-se imaginar que se desenvolvessem outras ações, como capacitações dos agricultores sobre a legislação, as necessidades de atender às normas sanitárias e de ter regularidade de entrega do produto, questões de formalização e estímulo ao associativismo e, até, possibilidades de produção de gêneros alternativos ou mesmo a realização de investimentos que permitam pequenas transformações dos produtos in natura pelos próprios agricultores.

Outro ponto a ser considerado diz respeito à periocidade e ao número de pontos de entrega dos produtos da agricultura familiar. Desde 2015, pode-se incluir o custo do transporte no limite de R\$20 mil que o agricultor pode vender para cada Entidade Executora do PNAE, mas, ao fazer isso, ele acaba por vender menor quantidade de sua produção. Nesse sentido, prefeituras que centralizem o recebimento dos alimentos favoreceriam mais a agricultura familiar do que aquelas que determinem a entrega muito descentralizada, por exemplo, em todas as unidades em que são servidas refeições. De forma semelhante, a obrigatoriedade de entrega de produtos várias vezes por semana prejudicaria a participação dos agricultores.

Sugere-se que a periodicidade de entrega definida nas chamadas públicas seja classificada em: i) entregas de 2 a 5 vezes por semana; ii) entregas semanais; iii) entregas de 1 a 2 vezes por mês; iv) outras, entregas algumas vezes no ano; v) não consta a informação. Já em relação aos pontos de entrega, propõe-se que as chamadas podem ser classificadas em: i) muito descentralizadas, com mais de 50 UR (unidades de recebimento); ii) descentralizadas, entre 11 e 50 UR; iii) pouco descentralizadas, entre 2 e 10 UR; iv) centralizadas, com uma única unidade de recebimento; v) não consta a informação.

Por fim, mas não menos importante, deve-se fazer uma avaliação quantitativa do cumprimento do artigo 14 por parte das prefeituras municipais. Propõe-se o seguinte agrupamento de prefeituras, de acordo com o percentual de compra de produtos da agricultura familiar em relação aos repasses do FNDE: i) refratárias ao artigo 14 - não adquirem nada dos agricultores familiares; ii) pouco aderentes ao artigo 14 - adquirem entre $0,1 \%$ e $10,0 \%$; iii) medianamente aderentes ao artigo 14, com porcentagens de aquisição entre $10,1 \%$ e $25 \%$; iv) aderentes 
ao artigo 14 - o porcentual de gastos fica entre $25,1 \%$ e $35 \%$; iv) prefeituras altamente aderentes ao artigo 14 - gastam além dos $35 \%$ dos repasses do FNDE, podendo chegar a $100 \%$ desses recursos ou mesmo mais, se incorporarem recursos próprios.

Parte dos quesitos acima apontados deve ser levantada através de entrevistas e questionários aplicados aos agentes públicos e sociais envolvidos com o artigo 14. Outra parte, mais significativa, pode ser obtida em documentos, com destaque para as chamadas públicas, muitas vezes disponíveis em sites das prefeituras municipais. Sua qualidade dependerá da boa descrição dos produtos pretendidos, da explicitação dos preços a serem praticados e dos critérios de desempate, de informações sobre periodicidade e pontos de entrega, da forma como ocorre a divulgação e da criação de rotinas que possibilitem aos agricultores saberem quando as chamadas serão lançadas.

Considerando-se que as chamadas públicas podem não se efetivar, parcial ou totalmente, ou mesmo que alguns de seus itens, desde que justificado, podem ser alterados posteriormente à sua divulgação, dois outros tipos de documentos devem ser acessados. Um deles refere-se às prestações de contas que as prefeituras anualmente encaminham ao FNDE sobre o PNAE, com ponto específico relativo ao artigo 14.

Outro tipo de documento passível de ser obtido diretamente com as prefeituras, são os contratos estabelecidos com os agricultores familiares ou suas organizações para fornecimento dos produtos contidos nas chamadas públicas. Esses contratos servem para confirmar se os quesitos das chamadas públicas são cumpridos, além de trazerem o endereço do agricultor ou de sua organização, permitindo verificar se a compra está sendo feita no município, na região, no estado ou fora do estado. Cabe ressaltar, neste ponto, que definir a abrangência da região ${ }^{7}$ não é sim-

7. Nas resoluções do FNDE fala-se em territórios rurais, que são os Territórios da Cidadania, cuja conformação é definida pelo Ministério do Desenvolvimento Agrário. Não é essa conotação que aqui se está dando ao termo região. ples (SONNINO e MARSDEN, 2006), e os autores desse artigo a consideram, sem maior rigor analítico e por sugestão de agricultores familiares, como composta por todos os municípios em um raio de até $100 \mathrm{~km}$ da sede do município executor do PNAE.

\subsection{Atratividade para os agricultores familiares}

A atratividade de participação como fornecedor de produtos para a alimentação escolar pode ser abordada para o conjunto de agricultores familiares ou para um agricultor isoladamente. No primeiro caso, considera-se que municípios com maiores populações e, consequentemente, maior alunado são mais atrativos, pois os valores a serem gastos na compra de produtos da agricultura familiar, em termos absolutos, seriam bem mais expressivos. Inclusive, municípios muito grandes e pertencentes a regióes metropolitanas podem ter área rural insignificante, fazendo-os demandar produtos de outros municípios.

A sugestão é que se procure confrontar o repasse do FNDE destinado à alimentação escolar para o município com a renda da agricultura familiar daquele local, que está disponível para 2006, ano de realização do último Censo Agropecuário (IBGE, 2012). Dando um passo adiante, podem-se verificar relações mais específicas, do consumo na alimentação escolar e da produção local de determinados produtos, como arroz, feijão, leite e outros mais.

Para o agricultor familiar, sua participação é estimulada pelo valor que arrecade no ano vendendo para a alimentação escolar. No início, com a resolução do FNDE no 38 de 2009 (BRASIL, $2009 b)$, previa-se que cada agricultor poderia vender no máximo até R\$ 9 mil por ano, valor que passou para R\$ 20 mil a partir da resolução do FNDE no 25 de 2012 (BRASIL, 2012), considerando-se o conjunto de entes públicos executores da alimentação escolar. Desde 2015, por meio da resolução do FNDE no 4 (BRASIL, 2015), esse

Nesse sentido, é preciso ponderar que os Territórios da Cidadania estão muito longe de abranger todo o território brasileiro, restando muitos municípios fora de seus limites. 
limite manteve-se em R $\$ 20$ mil, mas passou a ser relacionado à cada Entidade Executora. Ou seja, um agricultor familiar, atualmente, pode alcançar ganhos muito maiores, desde que forneça para mais de uma Entidade Executora.

Essa mudança merece discussão específica, à medida que pode beneficiar mais determinados agricultores ou suas organizações, mas limite a participação de maior número deles. Sugere-se que se acompanhe, ao longo dos anos, o número de agricultores familiares que participam do fornecimento de produtos para o artigo 14 em relação ao total de agricultores familiares de determinado município ou estado, número este registrado pelo Censo Agropecuário de 2006 (IBGE, 2012).

\subsection{Capacidade de participação dos agricultores}

Uma análise preliminar indicada diz respeito às características sociais e estruturais dos agricultores familiares da região ou do estado a que pertencem. Supõe-se que, em locais em que a agricultura familiar tem maior expressão econômica, os agricultores tenham maior integração aos mercados, capacidade de associação, de encaminhamento de reivindicações e, obviamente, um volume mais alto de produtos a serem entregues.

Embora o processo vigente de aquisição seja simplificado, é necessário o atendimento de questões burocráticas e legais pelos agricultores para participarem do PNAE, como dispor de Nota do Produtor e ser reconhecido formalmente como agricultor familiar através da DAP (Declaração de Aptidão ao Pronaf). Um levantamento sugerido é comparar o número de agricultores com DAP com o número de agricultores familiares do município, conforme o Censo Agropecuário de 2006 (IBGE, 2012). O acesso a outros programas públicos, como PAA e Pronaf, também pode ser um fator de estímulo à participação no PNAE e, portanto, convém ser levantado.

Em princípio, pode-se supor que a participação dos agricultores seria facilitada se os mesmos integrassem entidades coletivas, associações e cooperativas, dando-lhes maior possibilidade de acompanhamento das chamadas públicas e de atendimento às questões burocráticas, não comprometendo suas atividades essencialmente agrícolas, fato muitas vezes desconsiderado em várias análises.

Contudo, deve-se problematizar essa suposição. Ela pode não ser procedente, caso a associação ou cooperativa, de fato, não aja como representante do agricultor, mas se constitua em mero intermediário na comercialização de seu produto, não lhe repassando os preços mais altos obtidos na alimentação escolar. Para aferir essa situação não é suficiente analisar apenas os documentos das compras do artigo 14, sendo necessário obter informações diretamente dos agricultores familiares, bem como estudar a forma como atuam aquelas organizações, em especial como se relacionam com seus associados ou cooperados.

Um ponto já comentado deve ser aqui reforçado, qual seja, a capacidade dos agricultores processarem seus produtos e aumentarem a participação na alimentação escolar. Pode-se pensar em processamentos mais simples, como a higienização, o descascamento e corte e a embalagem de legumes e verduras, ou pouco mais complexos, que requereria a instalação de pequena agroindústria artesanal. Em muitos dos casos, seria necessária a realização de investimentos produtivos, que pode encontrar limitações nas condições financeiras dos agricultores e nas exigências normativas fiscais, sanitárias e ambientais para a instalação de agroindústria.

Uma última, mas muito importante questão, diz respeito à coincidência entre os calendários agrícola e escolar. Especialmente para os perecíveis, os produtos da agricultura familiar devem estar disponíveis naqueles momentos em que, na programação do cardápio, comporiam as refeições escolares. Já se comentou sobre as iniciativas que a gestão municipal pode adotar para aumentar aquela coincidência, mas tal fato pode ser reforçado pela reprogramação das atividades agropecuárias, ao longo do ano, pelos agricultores, não se olvidando das dificuldades que isso impõe. 


\subsection{Preços praticados}

Resolveu-se especificar essa discussão, procurando reforçar o óbvio e duplo significado do preço praticado, como gasto público ou como renda para os agricultores familiares. Ao realizar suas compras, estabelecida a qualidade requerida, as prefeituras devem procurar obter a maior quantidade possível de produtos alimentícios, ou seja, pagar menores preços. Por seu lado, o incentivo ao agricultor para participar do PNAE se daria com o recebimento de preços acima dos obtidos nos mercados convencionais.

Isso não necessariamente é incompatível. Basta entender que a compra é direta dos agricultores familiares ou de suas organizações, com seus produtos podendo ser remunerados pelas prefeituras ao nível dos preços praticados no varejo ou atacado em que tradicionalmente se realizam compras para a alimentação escolar. Pela compra direta e, muitas vezes, em canais mais curtos, seria diminuída a margem de comercialização, garantindo maiores preços aos produtores familiares.

Já se afirmou que os preços não podem ser objeto de disputa entre os agricultores familiares, devendo ser previamente fixados, considerando-se alguns critérios. Os preços deverão ser pesquisados em três mercados de âmbito local, inclusive, se possível, a feira do agricultor familiar. Se este levantamento de preços não puder ser feito localmente, ele deverá ser feito em âmbito territorial, estadual ou nacional, nesta ordem de prioridade. Os preços também devem ser acrescidos de eventuais gastos com embalagens, transporte e encargos que o agricultor possa vir a ter. No caso de produtos orgânicos, caso não haja possibilidade de se pesquisar o seu preço localmente, deve-se levantar os preços dos produtos tradicionais correspondentes e acrescer o seu valor em 30\%, segundo a resolução do FNDE no 4 de 2015 (BRASIL, 2015).

Visando verificar se os preços praticados no PNAE estão adequados, para produtos in natura é possível a comparação dos preços das chama- das públicas com aqueles recebidos pelo produtor agropecuário em mercados convencionais, registrados por órgãos públicos de economia agrícola existentes em diversos estados. Também é possível a comparação com preços no atacado, tomando por base informações de centrais públicas de abastecimento de hortigranjeiros. As dificuldades são maiores no caso dos produtos processados, sugerindo-se a comparação com informações oriundas de pesquisas sistemáticas visando compor índices de inflação ou com preços praticados nas licitações tradicionais para o PNAE.

Convém reforçar a percepção de que o diferencial de preços entre os mercados convencionais em que os agricultores vendem seus produtos e aqueles (mais altos, supostamente) obtidos no fornecimento para a alimentação escolar via artigo 14 pode estimular comportamentos oportunistas de alguns agentes sociais. Já se afirmou a possiblidade de cooperativas ou associações reterem para si esse diferencial, não o repassando para os agricultores. Contudo, há outras possibilidades, como a de se forjar a situação de agricultor familiar, através do "aluguel" ou uso indevido do número de DAP e mesmo procurar-se comercializar produtos não originários da agricultura familiar, mas comprados em centrais de abastecimento, por exemplo.

\section{Aplicação do artigo 14 nos estados do Paraná, Santa Catarina e São Paulo}

Apresentam-se alguns resultados obtidos pelos autores do artigo nos projetos de pesquisa/ extensão que desenvolveram nos últimos anos e que foram relacionados na Introdução. Os dados e informações foram obtidos em diferentes momentos e amostras e, portanto, não estão estritamente relacionados e não constituem um objeto de análise único. A intenção é revelar as análises possíveis de serem feitas, considerando-se diferentes subitens da seção anterior. 


\subsection{Ações das prefeituras municipais - características das chamadas públicas}

Um tipo de documento analisado nas pesquisas foram as chamadas públicas de 2012 e 2013. Para São Paulo e Santa Catarina usaram-se basicamente as informações obtidas em sites das prefeituras, coletadas em 2014, enquanto no Paraná a maior parte das chamadas públicas foi obtida via contato direto com as prefeituras municipais. O número de chamadas públicas obtidas está na Tabela 1. Esse número é maior que o dos municípios, pois, em muitos casos, foram obtidas duas ou mais chamadas de um mesmo município. Saliente-se que o número de municípios dos quais foram obtidas chamadas públicas em 2013 é superior a $5 \%$ do total de municípios de cada estado analisado que são: 645 em São Paulo, 399 no Paraná e 295 em Santa Catarina.

\subsubsection{Origem dos produtos}

A Tabela 2 revela a presença de produtos de origem animal ou vegetal nas chamadas públicas. ${ }^{8}$ Como se pode observar, a maior parte dos editais contém produtos de origem vegetal. Isto demonstra adequação às condições dos agricultores familiares, já que as normas sanitárias da produção animal são mais rigorosas e demandam maiores recursos financeiros para serem cumpridas. Chama a atenção, em Santa Catarina, a elevada proporção de chamadas com produtos de origem animal, indicando maior adequação de seus agricultores às normas sanitárias vigentes.

Na Tabela 3 verifica-se que a quantidade de produtos de origem vegetal é bem maior que a de origem animal. Os principais produtos de origem animal que apareceram nas chamadas foram ovos, leite, iogurte, bebida láctea, mel, queijos, doce de leite, ovo de codorna, diversos cortes de carne.

8. Nesse caso, a soma dos dois itens resulta em mais de $100 \%$, posto que uma mesma chamada pode conter produtos tanto de origem vegetal como animal. Com outros dados, situação semelhante pode ter acontecido.

\subsubsection{Grau de processamento dos produtos}

A Tabela 4 aponta que os produtos in natura estiveram presentes em mais de $80 \%$ das chamadas públicas. Evidencia-se que em Santa Catarina a participação de produtos com maior grau de processamento é mais importante do que nos outros dois estados, indicando que seus agricultores têm maiores facilidades de agregação de valor aos produtos agropecuários.

Na Tabela 5 também se pode notar a prevalência de produtos in natura, especialmente no estado de São Paulo. Novamente, evidencia-se que os agricultores catarinenses conseguem transformar mais seus produtos para participarem das chamadas públicas, seguidos pelos agricultores do Paraná.

\subsubsection{Periodicidade de entrega, pontos de entrega e informação de preços}

A Tabela 6 traz as informações relativas à periodicidade de entrega das chamadas públicas analisadas. Infelizmente, em muitos editais esta informação não aparecia ou estava muito imprecisa. Isto é uma falha importante, considerando-se que esta informação é vital para o planejamento e decisão do agricultor familiar.

Nos editais em que essa informação aparecia, prevaleceu a entrega semanal, que é compatível com as condições dos agricultores familiares e com a compra de vegetais in natura, que são os itens mais pedidos. A entrega mais de uma vez por semana se torna muito onerosa para os agricultores familiares. As entregas mais esporádicas estão relacionadas, no mais das vezes, com produtos não perecíveis.

A Tabela 7 traz o número de unidades de recebimento definido nos editais. A entrega centralizada aparece em aproximadamente metade dos editais de São Paulo e um pouco mais da metade no Paraná. Tal situação favorece o agricultor familiar, pois reduz as despesas com frete dos produtos. Em Santa Catarina, observa-se que a descentralização da entrega era maior do que nos outros dois estados. Destaque-se que bom número dos editais não trazia essa informação, especialmente neste último estado. 
Tabela 1. Número de chamadas públicas coletadas e número de municípios correspondentes em 2012 e 2013 , São Paulo, Paraná e Santa Catarina

\begin{tabular}{lccccccc}
\hline \multirow{2}{*}{ Estados } & \multicolumn{2}{c}{$\mathbf{2 0 1 2}$} & \multicolumn{2}{c}{ 2013 } & \multicolumn{2}{c}{ Total } \\
\cline { 2 - 8 } & Chamadas & Municípios & Chamadas & Municípios & Chamadas & Municípios \\
\hline São Paulo & 197 & 161 & 212 & 156 & 409 & 241 \\
Paraná & 21 & 11 & 43 & 26 & 64 & 37 \\
Santa Catarina & 39 & 29 & 94 & 46 & 133 & 75 \\
Total & 257 & 201 & 349 & 228 & 606 & 353 \\
\hline
\end{tabular}

Fonte: Elaboração dos autores (2015).

Tabela 2. Quantidade de chamadas públicas com produtos de origem animal ou vegetal, São Paulo, Paraná e Santa Catarina em 2012 e 2013

\begin{tabular}{|c|c|c|c|c|c|c|c|c|c|c|c|c|}
\hline \multirow{3}{*}{$\begin{array}{l}\text { Origem } \\
\text { Produto }\end{array}$} & \multicolumn{4}{|c|}{ São Paulo } & \multicolumn{4}{|c|}{ Paraná } & \multicolumn{4}{|c|}{ Santa Catarina } \\
\hline & \multicolumn{2}{|c|}{2012} & \multicolumn{2}{|c|}{2013} & \multicolumn{2}{|c|}{2012} & \multicolumn{2}{|c|}{2013} & \multicolumn{2}{|c|}{2012} & \multicolumn{2}{|c|}{2013} \\
\hline & No. & $\%$ & No. & $\%$ & No. & $\%$ & No. & $\%$ & No. & $\%$ & No. & $\%$ \\
\hline Animal & 110 & 55,8 & 118 & 55,7 & 13 & 61,9 & 24 & 55,8 & 33 & 84,6 & 80 & 85,1 \\
\hline Vegetal & 193 & 98,0 & 204 & 96,2 & 17 & 80,3 & 42 & 97,7 & 39 & 100,0 & 91 & 96,8 \\
\hline
\end{tabular}

Fonte: Elaboração dos autores (2015).

Tabela 3. Quantidade de produtos de origem animal e vegetal nas chamadas públicas de São Paulo, Paraná e Santa Catarina em 2012 e 2013

\begin{tabular}{|c|c|c|c|c|c|c|c|c|c|c|c|c|}
\hline \multirow{3}{*}{$\begin{array}{l}\text { Origem } \\
\text { Produto }\end{array}$} & \multicolumn{4}{|c|}{ São Paulo } & \multicolumn{4}{|c|}{ Paraná } & \multicolumn{4}{|c|}{ Santa Catarina } \\
\hline & \multicolumn{2}{|c|}{2012} & \multicolumn{2}{|c|}{2013} & \multicolumn{2}{|c|}{2012} & \multicolumn{2}{|c|}{2013} & \multicolumn{2}{|c|}{2012} & \multicolumn{2}{|c|}{2013} \\
\hline & No. & $\%$ & No. & $\%$ & No. & $\%$ & No. & $\%$ & No. & $\%$ & No. & $\%$ \\
\hline Animal & 216 & 5,0 & 191 & 4,0 & 28 & 7,0 & 109 & 11,4 & 332 & 25,1 & 717 & 22,9 \\
\hline Vegetal & 4.060 & 95,0 & 4.525 & 96,0 & 370 & 93,0 & 846 & 88,6 & 989 & 74,9 & 2.414 & 77,1 \\
\hline
\end{tabular}

Fonte: Elaboração dos autores (2015).

Tabela 4. Presença de produtos com diferentes graus de processamento nas chamadas públicas de São Paulo, Paraná e Santa Catarina em 2012 e 2013

\begin{tabular}{|c|c|c|c|c|c|c|c|c|c|c|c|c|}
\hline \multirow{3}{*}{$\begin{array}{c}\text { Nível de } \\
\text { processamento }\end{array}$} & \multicolumn{4}{|c|}{ São Paulo } & \multicolumn{4}{|c|}{ Paraná } & \multicolumn{4}{|c|}{ Santa Catarina } \\
\hline & \multicolumn{2}{|c|}{2012} & \multicolumn{2}{|c|}{2013} & \multicolumn{2}{|c|}{2012} & \multicolumn{2}{|c|}{2013} & \multicolumn{2}{|c|}{2012} & \multicolumn{2}{|c|}{2013} \\
\hline & No. & $\%$ & No. & $\%$ & No. & $\%$ & No. & $\%$ & No. & $\%$ & No. & $\%$ \\
\hline In natura & 172 & 87,3 & 174 & 82,1 & 19 & 90,5 & 39 & 90,7 & 34 & 87,2 & 81 & 86,2 \\
\hline Mínimo & 87 & 44,2 & 124 & 58,5 & 9 & 42,9 & 20 & 46,5 & 36 & 92,3 & 84 & 89,4 \\
\hline Médio & 59 & 30,0 & 92 & 43,4 & 6 & 28,6 & 8 & 18,6 & 18 & 46,2 & 46 & 48,9 \\
\hline Alto & 53 & 26,9 & 50 & 23,6 & 13 & 61,9 & 18 & 42,0 & 39 & 100,0 & 59 & 62,8 \\
\hline
\end{tabular}

Fonte: Elaboração dos autores (2015).

Tabela 5. Quantidade de itens nas chamadas públicas de acordo com o grau de processamento nos estados de São Paulo, Paraná e Santa Catarina, em 2012 e 2013

\begin{tabular}{|c|c|c|c|c|c|c|c|c|c|c|c|c|}
\hline \multirow{3}{*}{$\begin{array}{l}\text { Nível de } \\
\text { proces. }\end{array}$} & \multicolumn{4}{|c|}{ São Paulo } & \multicolumn{4}{|c|}{ Paraná } & \multicolumn{4}{|c|}{ Santa Catarina } \\
\hline & \multicolumn{2}{|c|}{2012} & \multicolumn{2}{|c|}{2013} & \multicolumn{2}{|c|}{2012} & \multicolumn{2}{|c|}{2013} & \multicolumn{2}{|c|}{2012} & \multicolumn{2}{|c|}{2013} \\
\hline & No. & $\%$ & No. & $\%$ & No. & $\%$ & No. & $\%$ & No. & $\%$ & No. & $\%$ \\
\hline In natura & 3.877 & 89,2 & 4.318 & 88,8 & 121 & 56,8 & 116 & 50,4 & 521 & 45,8 & 1.261 & 44,7 \\
\hline Mínimo & 184 & 4,2 & 218 & 4,5 & 61 & 28,6 & 74 & 32,2 & 234 & 20,6 & 655 & 23,2 \\
\hline Médio & 159 & 3,7 & 187 & 3,8 & 11 & 5,2 & 15 & 6,5 & 46 & 4 & 121 & 4,3 \\
\hline Alto & 127 & 2,9 & 140 & 2,9 & 20 & 9,4 & 25 & 10,9 & 337 & 29,6 & 784 & 27,8 \\
\hline
\end{tabular}

Fonte: Elaboração dos autores (2015). 
114 - Indicadores de Avaliação das Compras da Agricultura Familiar para Alimentação Escolar no Paraná, Santa Catarina e São Paulo

Tabela 6. Periodicidades de entrega registradas nas chamadas públicas de São Paulo, Paraná e Santa Catarina, 2012 e 2013

\begin{tabular}{|c|c|c|c|c|c|c|c|c|c|c|c|c|}
\hline \multirow{3}{*}{$\begin{array}{c}\text { Número de } \\
\text { entregas }\end{array}$} & \multicolumn{4}{|c|}{ São Paulo } & \multicolumn{4}{|c|}{ Paraná } & \multicolumn{4}{|c|}{ Santa Catarina } \\
\hline & \multicolumn{2}{|c|}{2012} & \multicolumn{2}{|c|}{2013} & \multicolumn{2}{|c|}{2012} & \multicolumn{2}{|c|}{2013} & \multicolumn{2}{|c|}{2012} & \multicolumn{2}{|c|}{2013} \\
\hline & No. & $\%$ & No. & $\%$ & No. & $\%$ & No. & $\%$ & No. & $\%$ & No. & $\%$ \\
\hline 2-5/semana & 16 & 8,1 & 20 & 9,4 & 0 & 0,0 & 0,0 & 0 & 1 & 2,6 & 4 & 4,3 \\
\hline Semanal & 81 & 41,1 & 81 & 38,2 & 2 & 9,5 & 2 & 4,7 & 6 & 15,4 & 11 & 11,7 \\
\hline 1 a $2 /$ mês & 15 & 7,6 & 17 & 8,0 & 0 & 0,0 & 0,0 & 0 & 8 & 20,5 & 13 & 13,8 \\
\hline Outro & 2 & 1,0 & 26 & 12,3 & 0 & 0,0 & 0,0 & 0 & 3 & 7,7 & 7 & 7,5 \\
\hline Não consta & 99 & 50,3 & 87 & 41,0 & 19 & 90,5 & 41 & 93,0 & 30 & 76,9 & 74 & 78,7 \\
\hline
\end{tabular}

Fonte: Elaboração dos autores (2015).

Tabela 7. Número de unidades de entrega registradas nas chamadas públicas de São Paulo, Paraná e Santa Catarina, 2012 e 2013

\begin{tabular}{|c|c|c|c|c|c|c|c|c|c|c|c|c|}
\hline \multirow{3}{*}{$\begin{array}{c}\text { Número } \\
\text { unidades } \\
\text { recebimento }\end{array}$} & \multicolumn{4}{|c|}{ São Paulo } & \multicolumn{4}{|c|}{ Paraná } & \multicolumn{4}{|c|}{ Santa Catarina } \\
\hline & \multicolumn{2}{|c|}{2012} & \multicolumn{2}{|c|}{2013} & \multicolumn{2}{|c|}{2012} & \multicolumn{2}{|c|}{2013} & \multicolumn{2}{|c|}{2012} & \multicolumn{2}{|c|}{2013} \\
\hline & No. & $\%$ & No. & $\%$ & No. & $\%$ & No. & $\%$ & No. & $\%$ & No. & $\%$ \\
\hline 1 & 97 & 49,2 & 109 & 51,4 & 12 & 57,1 & 43 & 64,6 & 7 & 18,0 & 8 & 8,5 \\
\hline 2 a 10 & 20 & 10,2 & 15 & 7,1 & 1 & 4,8 & 13 & 7,0 & 5 & 12,8 & 8 & 8,5 \\
\hline 11 a 50 & 31 & 15,7 & 49 & 23,1 & 0 & 0,0 & 0 & 0,0 & 6 & 15,4 & 14 & 14,9 \\
\hline Mais de 50 & 7 & 3,6 & 8 & 3,8 & 0 & 0,0 & 0 & 0,0 & 4 & 10,3 & 6 & 6,4 \\
\hline Não consta & 44 & 22,3 & 30 & 14,2 & 8 & 38,1 & 17 & 29,5 & 17 & 43,6 & 58 & 61,7 \\
\hline
\end{tabular}

Fonte: Elaboração dos autores (2015).

Pela lei no 11.947/2009 e resoluções do FNDE, o PNAE não deve fazer com que os agricultores familiares compitam entre si por preços, os quais devem ser fixados na chamada pública. Contudo, observou-se que muitas chamadas públicas não continham essa informação, situação mais grave em São Paulo. Neste estado, em 2012, apenas $27,4 \%$ das chamadas públicas informavam o preço, índice que se elevou para 37,2\% em 2013. No Paraná, esses números foram mais altos, respectivamente, de $85,7 \%$ e $93,0 \%$ e, em Santa Catarina, respectivamente, de $82,1 \%$ e $85,1 \%$.

Estes dados dão conta da dificuldade, ainda muito frequente, que os municípios têm para elaborar uma chamada pública. Este fato prejudica não só as próprias Entidades Executoras, mas, principalmente, os agricultores que ficam sem ter informações que amparem a sua avaliação sobre a viabilidade de sua participação ou não no Programa. Informações como preço a ser pago, número de locais e periodicidade de entrega facilitariam a decisão em se comprometer com a oferta de determinados produtos, considerando a logística, a frequência, a quantidade que deve ser entregue, em que datas e a que preço. Estas questões são elementares para a sua melhor organização e análise de custo/benefício.

\subsection{Ações das prefeituras municipais - cumprimento do artigo 14}

É possível perceber, pela Tabela 8, que o conjunto dos municípios dos três estados analisados vem aumentando a compra de produtos da agricultura familiar. No caso de Santa Catarina, seus municípios ultrapassaram o valor mínimo de $30 \%$ indicado pelo artigo 14. Os municípios paranaenses ficaram em situação intermediária e o menor nível de cumprimento, em 2014, foi registrado em São Paulo. Isso, como se verá na seção 3.5, parece estar relacionado com a importância relativa da agricultura familiar, que é maior em Santa Catarina e Paraná e menor em São Paulo.

Para fins comparativos, estudou-se o cumprimento do artigo 14 pelas secretarias estaduais da educação. A do Paraná aderiu fortemente à nova 
legislação e, em 2014, dos recursos recebidos do FNDE, já usava mais da metade na compra de produtos da agricultura familiar. No caso do estado de São Paulo, pelo contrário, registrava-se uma desconsideração quase que total com o artigo 14, que praticamente não venha sendo aplicado. Em Santa Catarina, a ação da secretaria estadual da educação era muito reduzida, abaixo de $1,0 \%$, o que não deixa de ser surpreendente dada a importância de sua agricultura familiar. Isto pode estar associado ao fato de o governo catarinense ter terceirizado para a iniciativa privada o fornecimento da alimentação escolar na rede estadual de ensino.

A Tabela 9 mostra que o número de municípios refratários ao artigo 14, que nada compraram de agricultores familiares, reduziu-se fortemente entre 2011 e 2014 nos três estados. Por outro lado, os municípios altamente aderentes, que compram mais que $35,1 \%$ da agricultura familiar, cresceram com muita intensidade nos três estados. No caso de Santa Catarina, os 174 municípios nessa situação, em 2014, representavam quase $60 \%$ do total de seus municípios.
Em pouquíssimos casos, percebeu-se que o poder público local procurava concatenar os diversos setores administrativos relacionados com a alimentação escolar. É comum o distanciamento e mesmo o conflito de orientações entre o setor de nutrição escolar, o departamento jurídico, o de licitação e o órgão de fomento agrícola.

\subsection{Ações das prefeituras municipais - origem dos agricultores familiares}

Nesse caso, a análise refere-se apenas ao estado de São Paulo e foi possível através da consulta a 128 contratos de fornecimento de alimentos pelos agricultores familiares de 2012 e 2013 para apenas 22 municípios de São Paulo.

A Tabela 10 mostra que a maior parte das prefeituras tinha contratos com agricultores do próprio município ou em municípios distantes até 100 quilômetros (regional). Em 2013, apenas seis prefeituras optaram por comprar produtos de outros estados (Paraná, Santa Catarina e Rio Grande do Sul). Interessante observar que quatro destes municípios têm mais de 500 mil

Tabela 8. Cumprimento porcentual do artigo 14, conjunto dos municípios e secretarias estaduais de educação (SEE), São Paulo, Paraná e Santa Catarina, 2011 a 2014

\begin{tabular}{lccccc}
\hline \multicolumn{1}{c}{ Ente Federativo } & $\mathbf{2 0 1 1}$ & $\mathbf{2 0 1 2}$ & $\mathbf{2 0 1 3}$ & $\mathbf{2 0 1 4}$ & Média \\
\hline SP - Municípios & 7,4 & 11,6 & 15,1 & 21,2 & 13,8 \\
SP - SEE & 2,5 & 0,0 & 0,0 & 0,1 & 0,6 \\
PR - Municípios & 16,6 & 19,6 & 17,1 & 26,3 & 19,9 \\
PR - SEE & 3,1 & 15,5 & 29,4 & 51,2 & 24,8 \\
SC - Municípios & 25,6 & 29,7 & 29,3 & 38,8 & 30,9 \\
SC - SEE & 0,0 & 1,4 & 0,7 & 0,8 & 0,7 \\
\hline
\end{tabular}

Fonte: Elaboração dos autores a partir de dados do FNDE (2015).

Tabela 9. Grupos de municípios de acordo com cumprimento porcentual do artigo 14 em 2011 e 2014, São Paulo, Paraná e Santa Catarina

\begin{tabular}{|c|c|c|c|c|c|c|}
\hline \multirow{2}{*}{$\begin{array}{c}\text { Nível de } \\
\text { cumprimento }\end{array}$} & \multicolumn{2}{|c|}{ São Paulo } & \multicolumn{2}{|c|}{ Paraná } & \multicolumn{2}{|c|}{ Santa Catarina } \\
\hline & 2011 & 2014 & 2011 & 2014 & 2011 & 2014 \\
\hline $0 \%$ & 345 & 175 & 107 & 70 & 59 & 33 \\
\hline $0,1-10,0 \%$ & 79 & 55 & 30 & 26 & 17 & 15 \\
\hline $10,1-25,0 \%$ & 88 & 114 & 57 & 62 & 33 & 27 \\
\hline $25,1-35,0 \%$ & 58 & 114 & 121 & 85 & 71 & 46 \\
\hline Mais $35,1 \%$ & 55 & 179 & 82 & 155 & 111 & 174 \\
\hline
\end{tabular}

Fonte: Elaboração dos autores a partir de dados do FNDE (2015). 
Tabela 10. Local do estabelecimento dos agricultores familiares fornecedores de alimentos para prefeituras de São Paulo, 2012 e 2013

\begin{tabular}{|c|c|c|c|c|c|c|}
\hline \multirow{2}{*}{ Local do Estabelecimento } & \multicolumn{2}{|c|}{2012} & \multicolumn{2}{|c|}{2013} & \multicolumn{2}{|c|}{ Total } \\
\hline & Número & $\%$ & Número & $\%$ & Número & $\%$ \\
\hline Municipal & 10 & 66,7 & 12 & 57,1 & 14 & 63,6 \\
\hline Regional & 11 & 73,3 & 17 & 81,0 & 17 & 77,3 \\
\hline Estadual & 4 & 26,7 & 7 & 33,3 & 8 & 36,4 \\
\hline Outro estado & 2 & 13,3 & 6 & 28,6 & 6 & 27,3 \\
\hline
\end{tabular}

Fonte: Elaboração dos autores (2015).

habitantes, um entre 100 mil e 500 mil e, outro menos, de 20 mil.

Os produtos fornecidos do próprio estado englobavam produtos in natura como legumes, verduras, frutas e ovos, principalmente, bem como alguns processados como vegetais minimamente processados, mel, doce de banana, bebida láctea, iogurte, queijos e suco de laranja. Santa Catarina forneceu maçã para São Paulo, Paraná, arroz parbolizado e queijo, e o Rio Grande do Sul apresentou extensa lista, com muitos produtos muito processados: arroz, barra de cereal, bebida láctea, biscoitos, doce de leite, farinha de milho, feijão, leite em pó, macarrão, mel, óleo de soja e suco de uva.

Uma informação adicional é que dos R\$ 29,2 milhões gastos com o artigo 14 pelas prefeituras paulistas aqui consideradas em 2012 e 2013, R\$ 24,8 milhões, ou 84,8\%, foram usados com agricultores do próprio estado, 8,4\% com compras no Rio Grande do Sul, 5,7\% no Paraná e 1,2\% em Santa Catarina e nada de outros estados. Os dados mostram que a maioria dos recursos recebidos do FNDE circulou no próprio estado, embora o porcentual de compra em São Paulo tenha diminuído de 94,4\% em 2012 para 82,9\% em 2013.

\subsection{Atratividade para agricultores familiares}

Especificamente para São Paulo, Baccarin et al. (2011) informam que o FNDE repassou em 2010 para prefeituras e secretaria estadual da educação um total de R \$ 542,1 milhões para alimentação escolar, o que permitiria a compra de R \$ 162,6 milhões de alimentos dos agricultores familiares, caso o artigo 14 fosse integralmente cumprido. Esse último valor equivalia a 3,2\% da renda bruta da agricultura familiar do estado, apurada pelo Censo Agropecuário de 2006 (IBGE, 2012) e corrigida pela inflação para 2010.

Outra conta que pode ser feita refere-se ao número de agricultores que potencialmente poderiam ser contemplados. Supondo-se que não ocorresse compra de agricultores de outros estados, que se atingissem os 30\% do artigo $14 \mathrm{e}$ que cada agricultor participante do PNAE recebesse $\mathrm{R} \$ 20.000,00 /$ ano, o repasse para alimentação escolar do FNDE em 2014 permitiria atender 9.610 agricultores familiares em São Paulo, 2.612 no Paraná e 1.520 agricultores familiares em São Catarina (FNDE, 2015). Esses números correspondem a $6,4 \%, 0,9 \%$ e $0,9 \%$ dos agricultores familiares registrados pelo Censo da Agricultura Familiar 2006 (IBGE, 2012), respectivamente em São Paulo, Paraná e Santa Catarina. Portanto, o alcance dessa ação é baixo, ainda mais nos dois estados em que a agricultura familiar é relativamente mais importante.

Grande parte das prefeituras dos três estados, ao cumprir o artigo 14 (e gastando R\$ 20.000,00/ agricultor), beneficiaria pequeno número de agricultores, conforme Tabela $11.77,1 \%$ das prefeituras paulistas, 92,7\% das paranaenses e 93,2\% das catarinenses conseguiriam comprar de até 10 agricultores, revelando pequena capacidade de intervenção na renda de seus agricultores familiares. Apenas uma prefeitura, do município de São Paulo, conseguiria atender acima de 1.000 agricultores, exatamente 1.422 agricultores, bem acima daqueles existentes em sua área territorial. 
Tabela 11. Municípios classificados em faixas de acordo com número de agricultores atendíveis pela aplicação do artigo 14, São Paulo, Paraná, Santa Catarina, 2014

\begin{tabular}{|c|c|c|c|c|c|c|}
\hline \multirow{2}{*}{$\begin{array}{c}\text { Faixa de } \\
\text { agricultores }\end{array}$} & \multicolumn{2}{|c|}{ Municípios SP } & \multicolumn{2}{|c|}{ Municípios PR } & \multicolumn{2}{|c|}{ Municípios SC } \\
\hline & Número & $\%$ & Número & $\%$ & Número & $\%$ \\
\hline Até 5 & 397 & 62,3 & 343 & 86,2 & 249 & 84,4 \\
\hline 6 a 10 & 94 & 14,8 & 26 & 6,5 & 26 & 8,8 \\
\hline 11 a 20 & 67 & 10,5 & 17 & 4,3 & 11 & 3,7 \\
\hline 21 a 50 & 55 & 8,6 & 10 & 2,5 & 7 & 2,4 \\
\hline 51 a 100 & 17 & 2,7 & 1 & 0,3 & 2 & 0,7 \\
\hline 101 a 200 & 5 & 0,8 & 1 & 0,3 & 0 & 0,0 \\
\hline 201 a 500 & 1 & 0,2 & 0 & 0,0 & 0 & 0,0 \\
\hline 501 a 1000 & 0 & 0,0 & 0 & 0,0 & 0 & 0,0 \\
\hline Mais 1.000 & 1 & 0,2 & 0 & 0,0 & 0 & 0,0 \\
\hline
\end{tabular}

Fonte: Elaboração dos autores a partir de dados do FNDE (2015).

Quanto às secretarias estaduais da educação, com os mesmos parâmetros acima expostos, seria possível atender 501 agricultores em Santa Catarina, 1.056 no Paraná e 2.001 em São Paulo.

Não se deve esquecer que um número maior de agricultores familiares poderia ser contemplado se fosse usado mais do que $30 \%$ dos repasses do FNDE e se gastasse menos que R\$ 20.000,00/ano com cada agricultor. Aliás, número considerável de municípios e a secretaria de educação do Paraná, como já visto, tem usado acima de 30\% dos repasses do FNDE em favor de seus agricultores familiares.

Evidentemente, desconsiderando-se os necessários deslocamentos, os grandes municípios são muito mais atrativos para os agricultores familiares. De acordo com Cora e Belik (2012), as 100 maiores prefeituras brasileiras (1,7\% do total) recebem cerca de $30 \%$ dos recursos de alimentação escolar repassados aos municípios, sendo que 36 deles estão situados no estado de São Paulo.

Para ser avaliada em futuros estudos, estabelece-se a suposição de que as grandes cooperativas de agricultores familiares vão direcionar seus esforços especialmente para venda de alimentos às grandes cidades. E estas, por questões administrativas e operacionais, vão preferir fazer contratos com essas organizações que envolvem grande número de agricultores e, portanto, grande quantidade de alimentos a ser entregue, além de terem maior capacidade de processamento de seus produtos.

\subsection{Condições produtivas e organização dos agricultores}

As condições da agricultura familiar são diferenciadas entre os estados de São Paulo, Paraná e Santa Catarina. No primeiro, o valor da produção da agricultura familiar representava tão somente $15,7 \%$ do valor de toda a agricultura do estado, com maior expressão no caso de hortícolas, feijão e leite de vaca. Desde 1975, verifica-se em São Paulo grande expansão da área canavieira, o que se acentuou no presente século. Excluindo as pastagens, a cana-de-açúcar ocupa área pouco superior à soma da área de todas as outras atividades agrícolas e florestais do estado e sua produção ocorre em extensos estabelecimentos, inclusive com o arrendamento de terras de pequenos proprietários rurais (BACCARIN, BUENO e SILVA, 2014).

O Paraná registra 371.051 estabelecimentos agropecuários, sendo 302.907 (mais de 80\%) caracterizados como de agricultura familiar, responsáveis por mais de $40 \%$ do valor bruto da produção da agropecuária do estado, sendo que esse índice alcança 65,9\% na mesorregião sudoeste, considerada reduto da agricultura familiar no estado (PEREIRA e BAZOTTI, 2010). Os mesmos autores mostram que $75,5 \%$ produção do feijão-preto, $81,0 \%$ da mandioca, $67,6 \%$ do leite, $66,5 \%$ de aves e $62,2 \%$ da produção dos suínos vieram de agricultores familiares.

Dos três, Santa Catarina é o estado com maior importância da agricultura familiar, com $87 \%$ do 
número de estabelecimentos agropecuários e $64 \%$ do valor bruto da produção de sua agricultura (MATTEI, 2010). A agricultura familiar destaca-se pela participação expressiva na produção estadual de mandioca $(93 \%)$, leite $(87 \%)$, milho $(77 \%)$, feijão $(73 \%)$, frangos $(68 \%)$, suínos $(67 \%)$, bovinos (65\%) e arroz (64\%) (IBGE, 2012).

Para São Paulo, Baccarin et al. (2011) tinham levantado informações referentes à formalização dos seus agricultores familiares. Em 2011 foi constatado, conforme o Ministério de Desenvolvimento Agrário (MDA, 2011), que 97.717 agricultores familiares apresentaram DAP ativa em São Paulo, número expressivo frente aos 151.015 estabelecimentos de agricultura familiar elencados no Censo Agropecuário de 2006 (IBGE, 2012). Tal nível de formalização, muito provavelmente, é ainda maior no Paraná e em Santa Catarina.

As entrevistas realizadas com agentes sociais envolvidos com o artigo 14 revelam que as compras institucionais, do PAA e do PNAE, contribuíram para aumento da organização social, com a criação de associações e, em menor número, de cooperativas de agricultores familiares, bem como para a realização de investimentos em equipamentos que permitam o processamento mínimo de seus produtos. Também se percebeu que algumas daquelas instituições agem como meros intermediários na comercialização dos produtos obtidos pelos agricultores familiares, que não participam e influenciam de fato nas ações e resultados das associações.

\subsection{Preços recebidos pelos agricultores familiares}

Nessa seção as informações são exclusivas para São Paulo. Ao contrário do que impõe a regulamentação do artigo 14, como já visto, observou-se que muitas chamadas públicas não continham a informação dos preços dos produtos a serem adquiridos. Isso, além de revelar a má qualidade das chamadas públicas, fez com que se resumisse a análise de preços apenas àquelas prefeituras das quais se obteve os contratos de compra dos agricultores familiares.

De maneira geral, os preços praticados no artigo 14 se mostraram maiores que os observados no PAA e os registrados em nível de produtor pelo Instituto de Economia Agrícola (IEA) da secretaria de agricultura e abastecimento do estado de São Paulo.

Foi possível fazer uma comparação envolvendo maior número de produtos entre preços das chamadas públicas e os do atacado, registrados pela Central de Entrepostos e Armazéns Gerais do Estado de São Paulo (Ceagesp), basicamente produtos vegetais in natura e ovo de galinha. A Tabela 12 mostra que um número muito reduzido de produtos, apenas $2 \%$, contou com preços abaixo de $50 \%$ daqueles praticados na Ceagesp. Supondo que os preços no atacado costumam se situar em patamar superior ao dobro dos preços recebidos pelos agricultores, os resultados apontam que os preços obtidos nos contratos do artigo 14 são vantajosos aos agricultores familiares.

Tabela 12. Comparação dos preços dos contratos do artigo 14 de prefeituras paulistas com preços no atacado da Ceagesp, São Paulo, 2012 e 2013

\begin{tabular}{lcccccc}
\hline \multicolumn{1}{c}{$\begin{array}{c}\text { Faixa de Preço em } \\
\text { Relação Ceagesp }\end{array}$} & \multicolumn{2}{c}{2012} & \multicolumn{2}{c}{$\mathbf{2 0 1 3}$} & \multicolumn{2}{c}{ Total } \\
\cline { 2 - 7 } & Número & $\%$ & Número & $\%$ & Número & \% \\
\hline Até 50\% & 1 & 0,7 & 6 & 2,7 & 7 & 2,0 \\
De 50\% a 100\% & 46 & 33,8 & 68 & 30,9 & 114 & 32,0 \\
De 100\% a 150\% & 36 & 26,5 & 71 & 32,3 & 107 & 30,1 \\
Mais de 150\% & 53 & 39,0 & 75 & 34,1 & 128 & 36,0 \\
Total & 136 & 100,0 & 220 & 100,0 & 356 & 100,0 \\
\hline
\end{tabular}

Fonte: Elaboração dos autores (2015). 
Número expressivo, $36,0 \%$, dos preços superaram os da Ceagesp em mais de $50 \%$. Tal situação não indica, necessariamente, que as prefeituras estejam pagando na compra de produtos da agricultura familiar valores mais altos do que nas compras tradicionais para alimentação escolar. Muitas vezes, as prefeituras compram seus produtos a preço de varejo e não de atacado, como são os da Ceagesp.

\section{Considerações finais}

Entende-se que o artigo 14 da lei $\mathrm{n}^{\text {o }}$ 11.947/2009 e suas diversas regulamentações fizeram com que essa legislação brasileira se adequasse ao que na literatura especializada tem sido denominado de Home-Grown School Feeding - HGSF. Tal abordagem propõe que a execução da alimentação escolar se baseie na compra local de produtos de agricultores familiares, contribuindo para a elevação de sua renda, com efeitos positivos no desenvolvimento local, além de propiciar a aquisição de produtos in natura, melhorando a qualidade nutricional dos produtos consumidos pelo alunado.

Procurando colaborar para o desenvolvimento de uma metodologia para avaliação da aplicação do artigo 14, conforme os ditames da HGSF, sugeriu-se a elaboração de uma série de indicadores, seguido da aferição de boa parte deles, tomando por base a execução do programa de alimentação escolar por municípios de três estados brasileiros, Paraná, Santa Catarina e São Paulo.

Em relação à eficiência na execução do artigo 14, em especial a análise das chamadas públicas permitiu observar que ainda existem dificuldades e debilidades nas ações das prefeituras. Evidenciou-se, em grande número das CPs, que informações como a periodicidade, número de locais para entrega e preços a serem pagos estavam ausentes. Isso desestimula a participação dos agricultores familiares no PNAE, já que não conseguem saber se ele vale a pena ou não do ponto de vista econômico. Entretanto, as características predominantes nas chamadas públicas, quando elas estavam explicitadas, se mostraram favoráveis aos agricultores familiares, como a exigência de entrega semanal e centralizada de produtos, o que favorece a logística e diminuição de custo por parte dos agricultores.

Em raríssimos casos, conseguiu-se estabelecer uma ação conjunta dos setores de alimentação escolar e de fomento à agricultura, o que poderia favorecer que se demandasse e se consumisse mais produtos alimentícios do próprio município. Constataram-se também reações contrárias de assessoria jurídica e do setor de licitação em substituir as licitações convencionais pela chamada pública.

Quanto à eficácia em alcançar os seus objetivos, identificou-se que os municípios, entre 2011 e 2014, aumentaram o nível de cumprimento do artigo 14, com alguns ultrapassando o limite mínimo de 30\% de compras de alimentos da agricultura familiar. Contudo, constatou-se que, em 2014, ainda existiam prefeituras totalmente refratárias ao programa, que nada adquiriam da agricultura familiar.

Ficou evidenciada a má vontade de algumas administrações em mudarem suas rotinas administrativas e aderirem ao artigo 14. Preferem continuar comprando produtos altamente processados, que exigem menos manipulação pelos funcionários municipais, por meio de processo licitatório e de um pequeno número de empresas, no mais das vezes, localizadas fora do município.

Ao se comparar os três estados, o conjunto dos municípios de Santa Catarina apresentou um nível mais alto de cumprimento da legislação: em 2014 acima de 30\%, seguido pelos do Paraná e, por último, os de São Paulo. Não coincidentemente, a importância relativa dos agricultores familiares, acompanhada do seu poder de reivindicação, é maior em Santa Catarina, seguido pelo Paraná e, depois, São Paulo.

Podem-se levantar algumas razões para o não cumprimento do artigo 14 por parte de algumas prefeituras. A legislação é relativamente nova, tendo começado a ser aplicada em 2010, exigindo um período de aprendizagem tanto dos gestores 
municipais quanto dos agricultores familiares. Outra explicação é um posicionamento contrário de administrações municipais à nova legislação, que foi estabelecida em termos federais. Até o momento não se estabeleceu punição às prefeituras que não cumpriram o artigo 14, até porque cortar recursos repassados pelo FNDE atingiria os alunos, que contariam com menos produtos na alimentação escolar.

Quanto ao tipo de gênero alimentício solicitado pelas CPs, percebeu-se que em Santa Catarina e no Paraná havia mais demanda das prefeituras por produtos de médio e alto grau de processamento, bem como pelos de origem animal, em comparação ao verificado em São Paulo. Muito provavelmente, isto é fruto do maior nível organizacional e de investimentos já concretizados em equipamentos industriais por parte das associações e cooperativas de agricultores familiares daqueles dois estados. Mas, em linhas gerais, observou-se que predominavam produtos de origem vegetal e in natura ou minimamente processados, que têm normas sanitárias mais simples e não necessitam de equipamentos sofisticados para o seu processamento, ao contrário do que se observa em grande parte dos produtos de origem animal. Identifica-se, portanto, a adequação/eficiência das CPs neste quesito, pois estão solicitando produtos coerentes com os produzidos pelos agricultores familiares. O predomínio de produtos in natura ou com baixo grau de processamento nas chamadas públicas também é um indício de que a nova legislação está permitindo que as prefeituras atinjam a meta de melhoria nutricional da alimentação escolar, apontando para a eficácia do programa.

Em análise específica para o estado de São Paulo, pode-se perceber que as prefeituras compram a maior parte dos produtos de agricultores familiares do próprio ou de municípios próximos, favorecendo o desenvolvimento local. Pagam pelos produtos valores relativamente altos em relação aos preços agrícolas, mas não tendem a extrapolar os preços de atacado ou de varejo.

Entretanto, constatou-se, para os três estados considerados, que os recursos do artigo 14, mesmo quando totalmente executados, conseguem beneficiar diretamente um número muito pequeno de agricultores do município, com exceção daqueles com grande população e alunado, o que não é a realidade de grande maioria dos municípios brasileiros. A efetividade do artigo 14 em proporcionar elevação de renda ao conjunto de agricultores familiares é, no mais das vezes, pequena.

A aplicação do artigo 14 tem estimulado a constituição de associações e cooperativas de agricultores familiares e também que se realizem investimentos em máquinas e equipamentos que permitam a transformação dos produtos, facilitando a sua manipulação pelos serviços municipais de alimentação escolar.

Porém, também se colheram informações de que algumas cooperativas e associações passam a atuar como intermediários convencionais de comercialização, não repassando aos agricultores familiares os benefícios de preços mais altos obtidos no PNAE. Algumas cooperativas fornecedoras são de grande porte e, por terem agricultores familiares associados, obtêm DAP jurídica e podem participar da execução do artigo 14. Essas cooperativas conseguem fornecer produtos como leite em pó ou longa vida, achocolatados e óleo de soja, obtidos em grandes instalações fabris.

Por fim, são apresentadas algumas sugestões de aprimoramento da legislação e de sua aplicação, visando garantir-lhe maior alcance social. A combinação do artigo 14 com outros programas, como o PAA e feiras livres, contribuiria para que maior número de agricultores fosse beneficiado e deveria se constituir em uma diretriz da política pública municipal. Da mesma forma, seria importante o reforço da participação de órgãos de Assistência Técnica e Extensão Rural (ATER), atuando conjuntamente com nutricionistas, no planejamento do cardápio e na orientação aos agricultores familiares, de forma a adequar os calendários de compra e produção de alimentos da agricultura familiar.

É importante que se estude com mais profundidade e, se for o caso, se reavalie a regulamentação que permite que uma mesma organização de agricultores familiares entregue um volume 
financeiro de produtos por ano bem acima de R\$ 20 mil, fornecendo para várias Entidades Executoras do PNAE. A impressão que se tem é que isto vai concentrar a oferta de produtos alimentícios em grandes cooperativas detentoras de DAP jurídica. Com o mesmo espírito, sugere-se considerar alguns mecanismos operacionais para que as associações e cooperativas repassem aos seus agricultores familiares os benefícios de preços mais altos obtidos por meio do artigo 14 .

\section{Referências}

BACCARIN, J. G. et al. Alimentação Escolar e Agricultura Familiar: Alcance e Dificuldades para Implantação do Artigo 14 da Lei 11.947/2009 no Estado de São Paulo. In: Congresso da Sociedade de Economia, Administração e Sociologia Rural (SOBER), 49., 2011, Belo Horizonte. Anais... Belo Horizonte: SOBER, 2011.

., BUENO, G. e SILVA, D. B. P. Uso da área nos estabelecimentos agropecuários face à expansão da agroindústria canavieira no estado de São Paulo, de 1990 a 2010. In: Congresso da Sociedade de Economia, Administração e Sociologia Rural (SOBER), 52., 2014, Goiânia. Anais eletrônicos... Brasília: SOBER, 2014. Disponível em: <http://icongresso.itarget.com.br/ useradm/anais/?clt=ser.4>. Acesso em: 25 set. 2015.

BEVILAQUA, K. e TRICHES, R. M. Implicações da venda de gêneros alimentícios ao Programa de Alimentação Escolar nos aspectos de renda e organização dos agricultores familiares. In: CONGRESSO DA SOCIEDADE BRASILEIRA DE SISTEMAS DE PRODUÇÃO (SBSP), 10., 2014, Foz do Iguaçu. Anais eletrônicos... Pelotas: SBSP, 2014. Disponível em: < http:// sbspanais.com.br/uploads/artigos/Resumo\%20(113). pdf >. Acesso em: 15 mai. 2015.

BEZERRA, O. M. P. A. et al. Promoção da aquisição de produtos da agricultura familiar para a alimentação escolar em Territórios da Cidadania de Minas Gerais e Espírito Santo. Revista de Nutrição, Campinas, v. 26, n. 3, p. 335-342, mai.jun. 2013.

BRASIL. Lei no 10.696, de 2 de julho de 2003. Dispõe sobre a repactuação e o alongamento de dívidas oriundas de operações de crédito rural, e dá outras providências. Diário Oficial [da] República Federativa do Brasil, Brasília, DF, 3 jul. 2003. Disponível em: <http:// www.planalto.gov.br/ccivil_03/leis/2003/L10.696.htm>. Acesso em: 11 out. 2015.
. Ministério da Educação. Fundo Nacional de Desenvolvimento da Educação. Resolução/CD/FNDE no 32, de 10 de agosto de 2006. Estabelece as normas para a execução do Programa Nacional de Alimentação Escolar - PNAE. Diário Oficial [da] República Federativa do Brasil, Brasília, DF, 17 ago. 2006. Disponível em: $<$ http://portal.in.gov.br/>. Acesso em: 12 dez. 2014.

. Lei no 11.947 , de 16 de junho de 2009. Dispõe sobre o atendimento da alimentação escolar e do Programa Dinheiro Direto na Escola aos alunos da educação básica e dá outras providências. Diário Oficial [da] República Federativa do Brasil, Brasília, DF, 17 jun. 2009a. Disponível em: <http://portal.in.gov.br/>. Acesso em: 20 ago. 2013.

Ministério da Educação. Fundo Nacional de Desenvolvimento da Educação. Resolução/CD/ FNDE no 38, de 16 de julho de 2009. Dispõe sobre o atendimento da alimentação escolar aos alunos da educação básica no âmbito do Programa Nacional de Alimentação Escolar - PNAE. Diário Oficial [da] República Federativa do Brasil, Brasília, DF, 17 jul. 2009b. Disponível em: < http://portal.in.gov.br/>. Acesso em: 18 abr. 2015.

. Ministério da Educação. Fundo Nacional de Desenvolvimento da Educação. Resolução/CD/FNDE $\mathrm{n}$ - 25, de 4 de julho de 2012. Altera a redação dos artigos 21 e 24 da Resolução no 38, de 16 de julho de 2009, no âmbito do Programa Nacional de Alimentação Escolar (PNAE). Diário Oficial [da] República Federativa do Brasil, Brasília, DF, 5 jul. 2012. Disponível em: <http://portal. in.gov.br/>. Acesso em: 17 ago. 2015.

Ministério da Educação. Fundo Nacional de Desenvolvimento da Educação. Resolução/CD/ FNDE no 26, de 17 de junho de 2013. Dispõe sobre o atendimento da alimentação escolar aos alunos da educação básica no âmbito do Programa Nacional de Alimentação Escolar - PNAE. Diário Oficial [da] República Federativa do Brasil, Brasília, DF, 18 jun. 2013a. Disponível em: <http://portal.in.gov.br/>. Acesso em: 14 fev. 2015.

. Ministério da Educação. Fundo Nacional de Desenvolvimento da Educação. Resolução/CD/FNDE no 4, de 2 de abril de 2015. Altera a redação dos artigos 25 a 32 da Resolução/CD/FNDE no 26, de 17 de junho de 2013 no âmbito do Programa Nacional de Alimentação Escolar (PNAE). Diário Oficial [da] República Federativa do Brasil, Brasília, DF, 8 abr. 2015. Disponível em: <http:// portal.in.gov.br/>. Acesso em: 23 set. 2015.

BUNDY, D. et al. Rethinking school feeding: social safety nets, child development, and the education sector. Washington: World Bank, 2009. 
CORA, M. A. J. e BELIK, W. (Orgs). Projeto Nutre $S P$ : análise da inclusão da agricultura familiar na alimentação escolar no estado de São Paulo. São Paulo: Instituto Via Pública, 2012.

ESPEJO, F., BURBANO, C. e GALLIANO, E. HomeGrown School Feeding: a framework to link school feeding with local agricultural production. Rome: WFP, 2009.

FAO - Food and Agricultural Organization. Alimentación escolar y las posibilidades de compra directa de la agricultura familiar: estudio de caso de ocho países. Programa de Cooperación Internacional Brasil-FAO. Brasília: Representação da FAO, 2013.

FNDE - Fundo Nacional de Desenvolvimento da Educação. Dados Agricultura Familiar 2011-2014. Brasília: FNDE, 2015. Disponível em: < http://www.fnde.gov.br/ programas/alimentacao-escolar/alimentacao-escolarconsultas/dados-da-agricultura-familiar $>$. Acesso em: 20 set. 2015.

IBGE - Instituto Brasileiro de Geografia e Estatística. Censo Agropecuário 2006: Brasil, Grandes Regiões e Unidades da Federação. Segunda Apuração. Rio de Janeiro: IBGE, 2012.

MARINHO, A. e FAÇANHA, L. O. Programas sociais: efetividade, eficiência e eficácia como dimensões operacionais da avaliação. Rio de Janeiro: IPEA. Texto para Discussão 787, abril de 2001.

MATTEI, L. Novo retrato da agricultura familiar em Santa Catarina. In: VIEIRA, L. M. Síntese Anual da Agricultura de Santa Catarina 2009-2010. Florianópolis: EPAGRI, 2010. p. 25-35.

MDA - Ministério do Desenvolvimento Agrário. Sistema de Extrato da DAP. Brasília: MDA, [201-]. Disponível em: $<$ http://smap13.mda.gov.br/ExtratoDap > . Acesso em: 18 mar. 2011.

MONTEIRO, C. A. et al. A new classification of foods based on the extent and purpose of their processing. Cadernos de Saúde Pública, Rio de Janeiro, v. 25, n. 11, p. 2039-2049, nov. 2010.
PEREIRA, V. V. V. R. e BAZOTTI, A. Ruralidade, agricultura familiar e desenvolvimento. Nota técnica do IPARDES, Curitiba, n. 16, p. 1-45, nov. 2010.

SÃO PAULO. Secretaria da Educação do Estado de São Paulo. Parceria entre Estado e municípios garante alimentação escolar para estudantes. Disponível em: $<$ http://www.educacao.sp.gov.br/alimentacaoescolar >. Acesso em: 15 set. 2015.

SARAIVA, E. B. et al. Panorama da compra de alimentos da agricultura familiar para o Programa Nacional de Alimentação Escolar. Ciência e Saúde Coletiva, Rio de Janeiro, v. 18, n. 4, p. 927-936, abr. 2013.

SOARES, F. V. et al. Structured Demand and Smallholder Farmers in Brazil: the Case of PAA and PNAE. Brasília: IPC/WFP, 2013.

SONNINO, R. e MARSDEN, T. K. Beyond the divide: rethinking relations between alternative and conventional food networks in Europe. Journal of Economic Geography, Oxford, UK, v. 6, n. 2, p. 181-189, apr. 2006.

TRICHES, R. M. Repensando o mercado da alimentação escolar: novas institucionalidades para o desenvolvimento rural. In: GRISA, C. e SCHNEIDER, S. (Orgs.). Politicas públicas de desenvolvimento rural no Brasil. Porto Alegre: Editora da UFRGS, 2015. p. 181-200.

e GRISA, C. Entre mudanças e conservadorismos: uma análise dos Programas de Aquisição de Alimentos (PAA e PNAE) a partir da retórica de intransigência. Revista NERA, Presidente Prudente, v. 18, n. 26, p. 10-27, jan./jun. 2015.

e SCHNEIDER, S. Desestruturar para construir: interfaces para a agricultura familiar acessar o programa de alimentação escolar. Estudos Sociedade e Agricultura (UFRJ), Rio de Janeiro, ano 20, v. 1, p. 66-106, abr. 2012.

SCHNEIDER, S. e SIMÕES, E. Aquisições públicas em Cabo Verde: desafios e potencialidades para o desenvolvimento rural. Revista Angolana de Sociologia, Luanda, Angola, n. 11, p. 63-80, 2013. 